\title{
3D Elemental Mapping using X-Ray Spectrometry in a Dual Beam-Focused Ion Beam
}

\author{
J. Wagner,* M. Hunková, ${ }^{*}$ M. Schmied, ${ }^{*}$ H. Mulders, ${ }^{* *}$ and M. Novak** \\ *Research Institute for Electron Microscopy and Fine Structure Research, Graz University of \\ Technology, julian.wagner@,felmi-zfe.at, Graz, A-8010, Austria
}

** FEI Company, jim@nl.feico.com, 5600 KA Eindhoven, The Netherlands

While micro- and nanotechnology present many exciting opportunities for materials science, they also present significant challenges for characterization. These challenges arise because optimizing the functionality of materials often depends on a precise control of the size, shape, chrystal structure and composition of the material being synthesized. Therefore many analysing methods were established in order to characterise solids in an appropriate way [1].

In this work we present the development of a new tomographic elemental analysing method using a dual beam-focused ion beam (DBFIB, Nanolab Nova200, FEI). We aim for collecting three dimensional data from a maximum volume of $20 \mu \mathrm{m} \times 20 \mu \mathrm{m} \times 20 \mu \mathrm{m}$ and the method should be able to run fully automated. The DBFIB instrument combines scanning electron microscopy and precisely focused ion beam etch and deposition. It is a complete nanotechnology laboratory in one tool and can be used for nanoscale prototyping, nano-machining, characterization and nano-analysis. However, for a 3D elemental map the focused ion beam cuts the specimen slice by slice and the visible cross section is imaged and mapped via the electron beam and the energy dispersive X-ray spectrometer (EDXS - EDAX, Genesis) as shown in figure 1a. In this context one has to meet a lot of challenges:

Specimen drift (fig. 1b), contrast change, the logistic work cycle, shadowing and redeposition effects (fig. 2) accompanied by the correct milling setups, the right take-off angle, post processing tools and correction methods have to be set into an optimized relationship and therefore tested and documented each for itself. Shadowing and redeposition effects for instance can be avoided by milling an "U-pattern" surrounding the interesting area (figure 3a) [2].

Another great amount of work deals with post processing methods. For example the specimen drift and changes in contrast between two slices are corrected with a specially developed script in the program „Digital Micrograph” (GATAN, Pleasanton, USA) [3]. First results are shown in figure 3b and illustrate the calcium distribution in a calcium-magnesium-titaniumoxide ceramic (specimen EPCOS, Deutschlandsberg - Austria; reconstructed using AMIRA-Software, TGS, San Diego, USA). However, in the near future this analysing method could be a helpful tool for investigations of the functional properties hidden in new structures, composites, nanomaterials and biological tissues.

\section{References}

[1] B. J. Inkson et al., Journal of Microscopy, Vol. 201, Pt 2, February 2001, pp. 256-269

[2] L. Holzer et al., Journal of Microscopy, Vol. 216, Pt 1, October 2004, pp. 84-95

[3] The aid of Digital Micrograph scripts written by Bernhard Schaffer is gratefully acknowledged. 

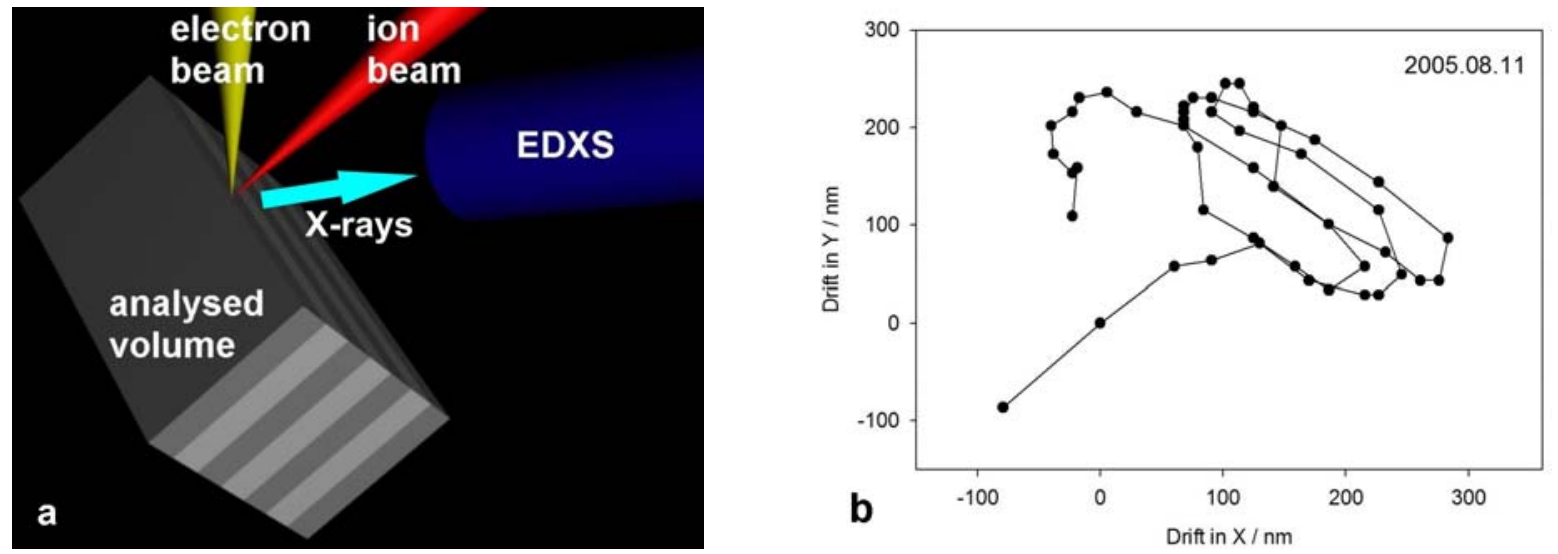

Fig. 1. a) Scheme of the 3D elemental map process. b) Drift during "Auto slice\&view " procedure of a $(\mathrm{Ca}) \mathrm{MgTiO}_{\mathrm{x}}$ ceramic (500 minutes, 50 slices, $\left.20 \times 15 \times 6 \mu \mathrm{m}\right)$.
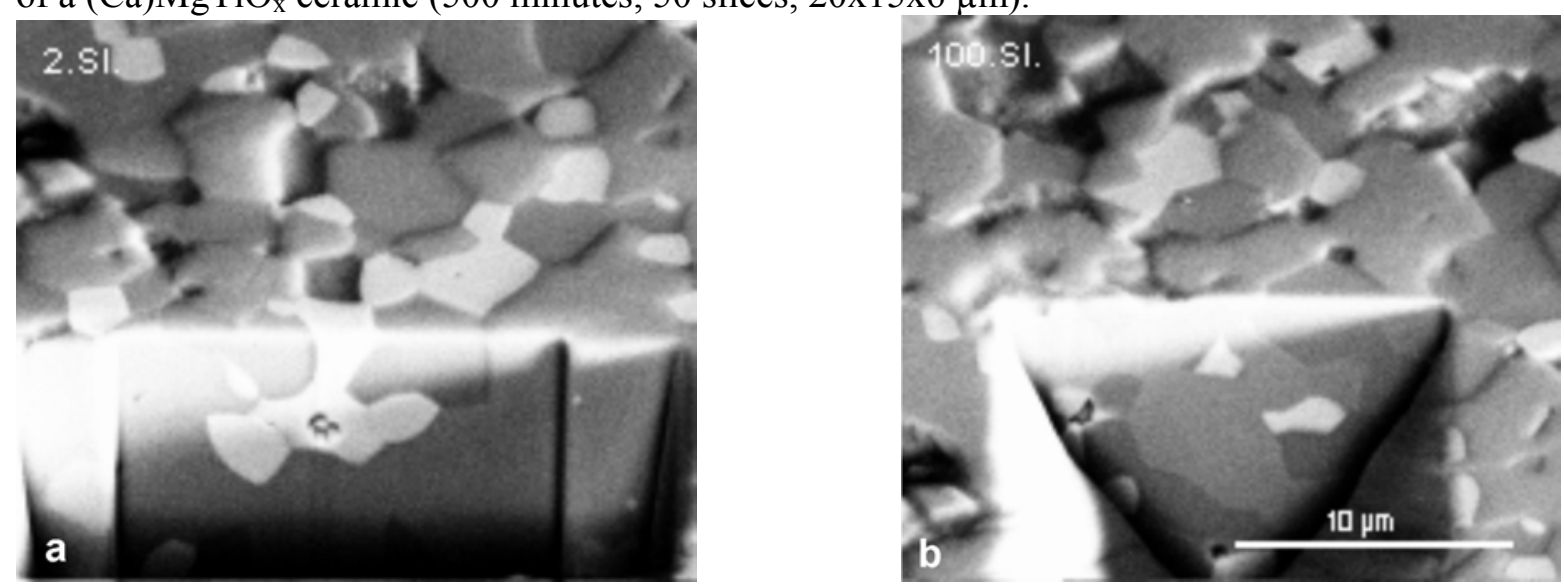

Fig. 2. BSE images of a $(\mathrm{Ca}) \mathrm{MgTiO}_{\mathrm{x}}$ ceramic showing shadowing and redeposition effects after a) 2 slices and b) 100 slices $(15 \times 5 \times 20 \mu \mathrm{m})$.
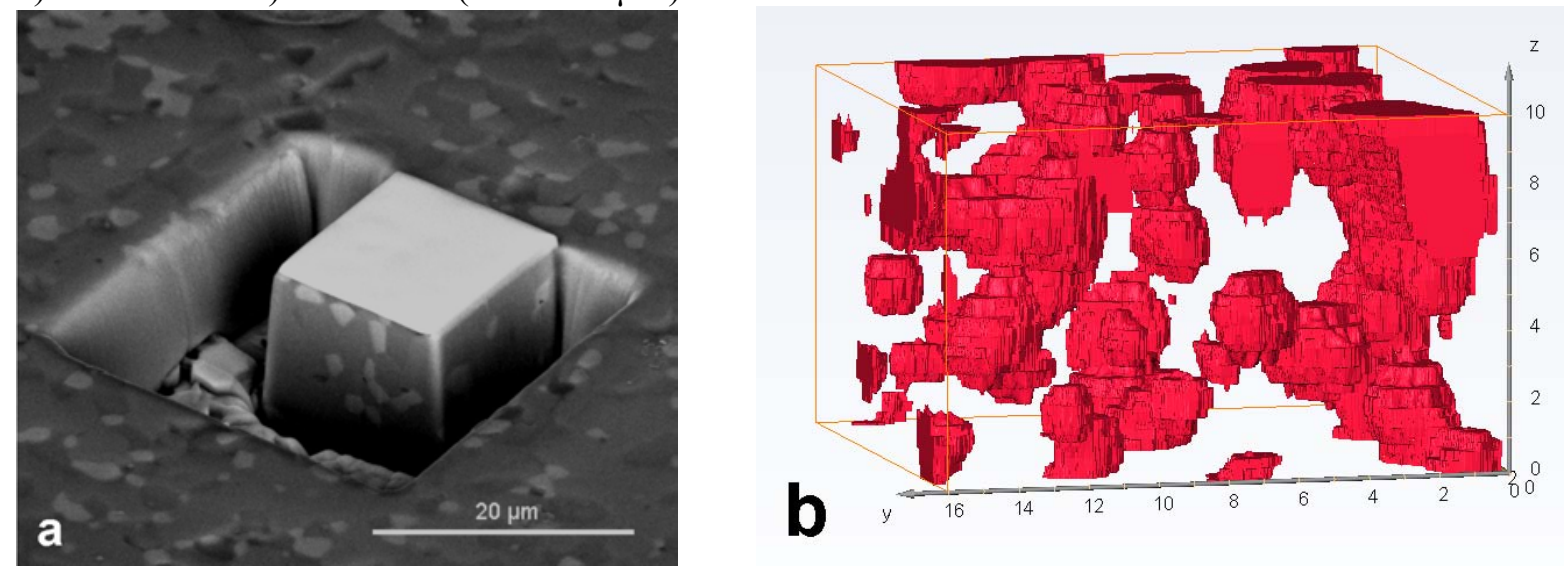

Fig. 3. a) "U-pattern" surrounding the interesting area to avoid shadowing and redeposition. b) 3 dimensional $\mathrm{Ca}$ distribution in a $(\mathrm{Ca}) \mathrm{MgTiO}_{\mathrm{x}}$ ceramic reconstructed using AMIRA software and EDXS elemental mapping (axis division in microns). 